\title{
Genetics services in a social, ethical and policy context: a collaboration between consumers and providers
}

Dorothy C Wertz, and Robin Gregg The Eunice Kennedy Shriver Center for Mental Retardation, Inc, Waltham, Massachusetts, USA

\begin{abstract}
We report a unique, collaborative effort by users and providers of genetic services to arrive at outlines for optimal ethics and clinical practice. Using focus groups of consumers (users) and providers (held separately), a provider-consumer project team developed 1) a consumer wish list, 2) an experientially based ethical overview of situations arising in practice, and 3) detailed suggestions for consumer-provider interactions in clinical settings. Consumers were primarily interested in accurate information, respect for persons, a smoothly functioning team, with the consumer as an equal member of the team, family integrity, and providers who knew the limits of their knowledge and were willing to refer. "Non-directive" counselling and privacy were not major issues in consumer focus groups; some thought providers should openly state their own opinions. Providers had a rather different list of priorities.

Books and papers on clinical ethics usually originate from bioethicists and physicians. This pilot project is unique in including consumers and providers equally.

(Fournal of Medical Ethics 2000;26:261-265)

Keywords: Genetic services; genetics and ethics; consumer-provider interaction; genetics and policy
\end{abstract}

Most ethical and service guidelines derive from recommendations of medical professionals or bioethicists. The voices of users of these services (or "consumers", as many prefer to be called in the United States) are rarely heard, either in codes of practice or codes of ethics. Although consumers have worked with providers on special projects, including producing a model informed consent form for breast cancer genetic testing, ${ }^{2}$ and workshops, ${ }^{3}$ there has been no comprehensive consumer-provider effort to describe "best practices" in genetics. Consumers' concerns may differ from professionals' concerns, and any outline of optimal services should reflect both.

In 1992, a group of consumers and providers in the New England Regional Genetics Group (NERGG) resolved to produce a joint consumerprovider document outlining optimal genetics services. The New England Regional Genetics Group is one of ten regional genetics groups in the United States funded by the Bureau of Maternal and Child
Health. It meets regularly to consider improvements to service delivery, exchange scientific information and make social and ethical statements about service provision, but its statements have no binding force. The New England Regional Genetics Group included four consumer representatives - mostly parents of children with genetic conditions - on its original steering committee over 20 years ago, and has maintained strong consumer representation.

The original working group for the optimising genetics services project was self-constituted, including, in addition to the principal investigator, four consumers, two genetic counsellors, two MD medical geneticists, and a public health representative. After replacements and additions during the four years of the project, the team (see Acknowledgements) included four consumers (both parents and adults with genetic conditions), five genetic counsellors (two with nursing degrees), two MD medical geneticists, a primary care physician, and a public health representative. The four consumers did a disproportionate share of the writing. As often happens in volunteer projects in which no one is paid, those with the most at stake made the largest contributions of time. Although fewer consumer than provider names appear on the list of team members who contributed over the life of the project, the consumer contribution was at least equal to provider contribution and probably outweighed it. After almost three years of meetings, most with greater attendance by consumers than providers, it is impossible to assign a weight to the contributions of each person.

Before beginning work on the document, the team held five focus groups, three for consumers (two groups of eight and one of 12, including one attended largely by African-Americans), ${ }^{4}$ one (nine persons) for doctoral-level geneticists, and one (ten persons) for master's-level genetic counsellors, a specialty that is strong in North America. The ideal number for a focus group is 6-10 persons. ${ }^{5}$ In all, 47 persons (none of them members of the project team) participated in the focus groups, which took place in three states. Consumers included both adults with or at high risk for genetic conditions, and parents of children with genetic conditions. Most were rank-and-file; none were officers of support groups. The project sought out ordinary con- 
sumers because their opinions were less likely to be influenced by literature or statements from organised patient groups. Inclusion of active support group members might have led to greater emphasis on "genetic discrimination" in insurance and employment and possibly also to some opposition to prenatal diagnosis from a disability point of view.

Focus groups are akin to group interviews. They allow people to express their views interactively, in the light of previous comments by other members of the group. Focus groups may elicit comments that would not come out in individual interviews. A facilitator, who tries to say as little as possible, makes sure that all elements of an agenda, or "script" are covered during the two-hour session. Participants are selected-through various networks - to include people as different from each other as reasonably possible. Focus groups are an accepted method of beginning a project when the basic concerns of the stakeholders involved are still unclear.

Concerns revealed by the focus groups appear in table 1 , in general order of importance. Consumer concerns (column A) differed considerably from provider concerns (column B). One of consumers' major concerns - vying for first place with respect for persons-was accuracy of information. Some had received inaccurate, inadequate, or fragmentary information from providers, including geneticists. Consumers wanted providers who "knew the limits" of their knowledge and who were willing to make early referrals to specialists. Consumers wanted a smoothly functioning team approach to care, with the consumer regarded as an expert member of the team-not an expert in terms of genetic knowledge, but an expert about the day-today symptoms, functioning, and responses to treatment of self or family member, a type of intimate knowledge possessed by few providers. Consumers stressed the education of ancillary personnel, such as receptionists, medical office managers, or deliverers of home oxygen and equipment, because these people are often a consumer's first contacts with the medical system. They should receive education in the basic ethics of interaction with consumers as well as in the importance of their roles as members of the team. Consumers also wanted holistic care that included maintaining the integrity of the family.

Several topics of intense concern to bioethicists and national commissions were missing from consumers' lists of concerns: these were privacy, non-directive counselling, and informed consent. Consumers mentioned privacy only as something that interfered with smooth teamwork, by making medical records difficult to transfer to the next specialist, who often had to re-do costly tests. They looked forward to the day of "smart cards" that would put their entire medical records on creditcard-sized pieces of plastic to be carried in their wallets. They expected medical professionals to provide some sort of guidance, not just information, but would have been highly annoyed if told what to do. Some thought that providers should tell consumers what they would do if in the consumer's situation, but only if the consumer asked. Consumers believed that providers should avoid facile judgments about prognosis or about consumers' values.

Providers were primarily concerned about social, economic, and time constraints on genetics services, access, availability of legal abortion, evaluation, setting, professional education, nondirectiveness, and support groups. Privacy and informed consent were also absent from their lists. Some concerns, such as team approach, integrity of family, effective communication, evaluation, and referrals, appeared on both lists, but in a different order.

Table 1 Topics of Concern to Consumers and Providers in Focus Groups (listed in order of importance)

\begin{tabular}{|c|c|c|c|}
\hline \multicolumn{2}{|c|}{ Column A Concerns of Consumers } & \multicolumn{2}{|c|}{ Column B Concerns of Providers } \\
\hline 1. & Respect for Persons & 1. & Multiple Constraints that Impede Ideal Services \\
\hline 2. & Accuracy of Information & 2. & Team Approach is Best \\
\hline 3. & Knowing When to Refer and Being Willing to do so & 3. & Access, Availability of Genetic Services \\
\hline 4. & $\begin{array}{l}\text { Knowing and Communicating own Limitations and } \\
\text { Abilities }\end{array}$ & 4. & Safe, Legal Abortion Must be Available and Accessible \\
\hline 5. & Describing Expectations at Beginning of Initial Session & 5. & $\begin{array}{l}\text { Spending Adequate Time: Preparation for Session, Initial } \\
\text { Session, Follow-up Sessions }\end{array}$ \\
\hline 6. & Avoiding Facile Judgements of Prognosis & 6. & Ongoing Evaluation \\
\hline 7. & $\begin{array}{l}\text { Making no Assumptions about Consumers' Choices or } \\
\text { Values }\end{array}$ & 7. & Professional Continuing Education Opportunities \\
\hline 8. & $\begin{array}{l}\text { Spending Adequate Time: Preparation for Session, Initial } \\
\text { Session, Follow-up Sessions }\end{array}$ & 8. & Referring Out Cases When Uncomfortable \\
\hline 9. & Education of Ancillary Personnel & 9. & Continuity of Care \\
\hline 10. & $\begin{array}{l}\text { Team Approach is Best, with the Consumer as an Equal } \\
\text { Member of the Team }\end{array}$ & 10. & Consumer Grievance Procedures \\
\hline 11. & Ongoing Evaluation & 11. & Importance of Setting \\
\hline 12. & Communication Skills & 12. & Pre-Test Counselling a Must \\
\hline 13. & $\begin{array}{l}\text { Holistic Awareness and Approach That Preserves } \\
\text { Integrity of the Family. }\end{array}$ & 13. & Directiveness vs Nondirectiveness \\
\hline \multirow[t]{2}{*}{14 . } & Addressing All Aspects of Consumer Situation(s) & 14. & $\begin{array}{l}\text { Familial/communal Aspect of Genetic Counselling } \\
\text { Importance of Support Groups, Allied and Community } \\
\text { Services }\end{array}$ \\
\hline & & 16. & Mentoring: A Step Toward Effective Services \\
\hline
\end{tabular}


Building on results of the focus groups, the project team met during the next three years to work out a comprehensive 100-page document, entitled Optimizing Genetics Services in a Social, Ethical, and Policy Context. ${ }^{6}$ The document has three parts: a consumer "wish list", a section on ethics, and a section on interactive aspects of practice. It is designed so that educators can pull out modules for training medical students, nurses, postdoctoral fellows, or consumer groups. All sections interweave perspectives from the disability community. In earlier working versions, the document spoke of "genetic encounters" rather than genetics services, reflecting the project team's view that visits to genetic clinics and other sources of information or help were at least two-way endeavours, with each party contributing to the encounter.

\section{Unique feature}

A unique feature of the final document is its attention to the kinds of details that make an interaction successful in the eyes of consumers: someone to care for a toddler while the parents receive genetic counselling, a place to stay overnight while making a decision about prenatal diagnosis or abortion, receptionists who are treated, and in turn treat consumers, with dignity. These practical, but important aspects of care are blended in with difficult ethical and social issues, such as effects of prenatal diagnosis on society or social inequality, or how to counsel a mother whose actions during pregnancy may have adversely affected the health of her child.

The first section describes consumers' experiences, wants, and needs. It steers a course between directive and non-directive approaches to counselling that reflects consumers' unique perspectives on non-directiveness. Most do not want to be given "information only", without guidance. Consumers stress the importance of not prejudging a prognosis, not making assumptions about people's values, and the need to preserve hope. The last part of this section guides consumers through the process of accepting a diagnosis and seeking help on their own.

\section{Ethics section}

The ethics section - the largest part of the document at 49 pages - offers comprehensive coverage of most issues arising in clinical genetics (but not research). This section was informed by professional and personal experience rather than by ethical theories. It perhaps best approximates Beauchamp and Childress's "action guides", which act as a pragmatic shorthand for principles. ${ }^{7}$ The group considered some statements by ethical commissions, ${ }^{8}$ professional societies, ${ }^{9}$ and legal experts ${ }^{10}$ in arriving at its own conclusions, many of which are consistent with other recent publications. ${ }^{11-13}$ The project team agreed on some difficult and controversial issues: 1) professionals may override patient confidentiality in certain limited situations to warn relatives about genetic risks, provided that there is a high risk of serious harm to relatives, as stipulated by the President's Commission $^{8}$ in 1983 ; 2) Children, including children awaiting adoption, should not have presymptomatic tests for adult-onset disorders; 3) Psychologically sensitive information should be disclosed to those concerned, if it does not threaten the integrity of the family; 4) Concerns of public safety may override individual confidentiality; 5) Newborn screening for treatable disorders should be mandatory; 6) Cost-benefit analyses, while useful in setting priorities for public health programmes, have many ethical limitations; 7) Prenatal diagnosis and selective abortion should be legal, available, and financially accessible to all, and 8) Education for professionals should always include experience with the lives of people with disabilities, outside a clinical setting.

The group also agreed that there is no feasible definition of "serious" disorders that can be applied to genetics services. Individuals, families, and professionals have widely varying concepts of the word "serious". Therefore it should not be used in an ethical or service context except with the stipulation that its definition is left to the individual or family receiving services.

The most difficult ethical issues on which the group had difficulty agreeing were: whether there should be limitations on the autonomy of physicians, for example, in regard to using prenatal diagnosis for sex selection; whether prenatal diagnosis will affect either society (through differential use by different social groups) or society's attitudes towards people with disabilities, and whether the optimal services described in the document can really exist, given that resources are not unlimited, unless middle-class people are willing to pay considerably more than they do now in order to support services for those less well off. Ultimately, the group agreed that prenatal diagnosis should not be used for sex selection (except in cases of sex-linked genetic disorders) and also that prenatal diagnosis may affect societal views of disability. Some physicians also saw a contradiction between consumers' desires for accurate information and their wishes that the provider preserve hope. Genetic counsellors believed that this could be resolved with empathic counselling, and the document describes this approach in some detail.

The final section on practice covers the full range of genetics services, from preconception to adult care, including genetic counselling, carrier, presymptomatic, and susceptibility testing, and prenatal diagnosis. This section is highly detailed with regard to the specifics of setting, content of information to be provided in counselling, context of follow up calls or letters, and the process of evaluation. For example, it suggests on-site child care at clinics, so that parents will not be counselled with screaming children on their laps, facilities for overnight stays near the clinic to allow thinking time between prenatal diagnosis and a possible abortion, and timing appointments to coincide with transportation schedules, etc. Respect for different cultural perspectives, use of interpreters, and 
"person-first" language (for example, "person with cystic fibrosis" rather than "cystic fibrosis case") are recommended.

\section{Optimal genetic counselling}

This section describes in some detail what should go into optimal genetic counselling, including some topics that are infrequently discussed: a description of what a child with a particular genetic condition will be like as an adult; effects on the marriage; effects on the child's siblings, and on family life; financial costs of care, and effects on the family's insurance and employment. These psychosocial issues - of great importance to consumers - are as rarely discussed in counselling today ${ }^{14}$ as they were 20 years ago. ${ }^{15}$

This section stresses the importance of adequate pre-test counselling, especially with regard to prenatal diagnosis. Women should be informed, before the initial blood test (maternal serum alpha fetoprotein or the "triple test") that screens for possible elevated risk, that this may be the first step on the road to a decision about abortion.

Although everyone on the project team agreed about the importance of patient and parent organisations ("support groups"), which sometimes provide the most useful and comprehensive information, professionals pointed out that some people do not feel comfortable with such groups. The usefulness of referrals to families with children with disabilities for help in making reproductive decisions remains debatable.

\section{Conclusion}

Optimizing Genetics Services is a unique document because of the apparently seamless collaboration in which consumers' views blend with those of providers. We heartily recommend further efforts of this type in other fields of medicine.

The document is not a medical/legal standard of care. Hence its subtitle, Suggestions from Consumers and Providers in the New England Regional Genetics Group. Even the word "recommendations" would be too strong for many professionals to accept. At this point in time, only a profession can create a standard of care, at least in the United States. To most physicians, "standard of care" is a legal term: it means the standard with which they will be compared in malpractice suits. Professional organisations are very protective of their powers to set such standards. From the beginning, physicians made it clear that the project team was not to step on their turf. But should professionals have exclusive self determination over standards of care, or should the people they serve have a role in creating such standards?

Although American consumers in particular, are autonomy-oriented and tend to regard any withholding of a requested service as a denial of patients' rights, ${ }^{16}$ the document is not a paean to unlimited autonomy. The duty to avoid harm generally takes precedence over rights to know or confidentiality if there is a conflict between ethical duties. It remains to be seen, however, who will pay for the optimal care described. Perhaps the most difficult ethical issue of all is whether Americans have sufficient sense of community to be willing to pay for others' enjoyment of the care that they desire for themselves.

\section{Acknowledgements}

This project was made possible by the New England Regional Genetics Group (NERGG) and supported by the Maternal and Child Health Bureau (Title V, Social Security Act), Health Resources and Services Administration, Department of Health and Human Services, Grant \# MCJ-251003-9/10/12.

Members of the project team were Betsy Anderson, Federation for Children with Special Needs, Boston, MA; Susan Z Berg, MS, DartmouthHitchcock Medical Center, Lebanon, NH; Robin J R Blatt, RN, MPH, Massachusetts Department of Public Health, Boston, MA; Dale Halsey Lea, RN, $\mathrm{MPH}$, Foundation for Blood Research, Scarborough, ME; Mia MacCollin, MD, Neuroscience Center, Massachusetts General Hospital, Charlestown, MA; Wayne A Miller, MD, Prenatal Diagnostic Center, Lexington, MA; Victoria Odesina, RN, MS, Sickle Cell Service, St Francis Hospital, Hartford, CT; Eileen Rawnsley, RN, BSN, DartmouthHitchcock Medical Center, Lebanon, NH; Ruth Ricker, Past President, Little People of America, Boston, MA; Margaret "Wendy" Ricker, EdD, Windham, ME; Kathryn Spitzer-Kim, MS, Genetic Counseling Program, Brandeis University, Waltham, MA; Barbara R West, MS, Vermont Regional Hemophilia Center, Burlington, VT; Hilary Worthen, MD, Internal Medicine, Cambridge City Hospital, Cambridge, MA.

We would also like to thank the 47 consumers and providers who participated in the focus groups.

Dorothy C Wertz, PhD, is Senior Scientist in Social Science, Ethics and Law, The Shriver Center for Mental Retardation, Waltham, MA,USA. Robin Gregg PhD, was formerly a postdoctoral fellow at the Shriver Center.

\section{References and notes}

1 National Action Plan on Breast Cancer Tissue Banking Working Group, with comments by the PRIM\&R/ARENA Tissue Banking Working Group. Model consent forms and related information on tissue banking from routine biopsies. Boston, MA: 1997.

2 Williamson C. The rise of doctor-patient working groups. British Medical fournal 1998;317:1374-7.

3 Schibeci R, Barns I, Shaw R, Davison A. Genetic medicine: an experiment in community-expert interaction. Fournal of Medical Ethics 1999;25:335-9.

4 Wertz DC. The difficulties of recruiting minorities to studies of ethics and values in genetics. Community Genetics 1998;1:175-9. 5 Morgan DL. Planning focus groups: focus group kit 2. London: Sage Publications, 1998: 71 .

6 Wertz DC, Gregg RW, eds. Optimizing genetics services in a social, ethical and policy context: suggestions from consumers and providers in the New England Regional Genetics Group. The Genetic Resource 1966;10 [special issue]. Available from Mary Genetic Resource 1966;10 [special issue]. Available from Mary MA 02460; email maryaten @mediaone.net

7 Beauchamp TL, Childress JR. Principles of biomedical ethics [4th ed]. New York: Oxford University Press, 1994. 
8 President's Commission for the Study of Ethical Problems in Medicine and Biomedical and Behavioral Research. Screenin and counselling for genetic conditions. Washington, DC: US Government Printing Office, 1983.

9 American Society of Human Genetics Board of Directors and American College of Medical Genetics Board of Directors. Points to consider: ethical, legal, and psychosocial implication of genetic testing in children and adolescents. American fournal of Human Genetics 1995;57:1233-41.

10 Annas GJ, Glantz LH, Roche PA. The Genetic Privacy Act and commentary. Boston, MA: Health Law Department, Boston University School of Public Health, 1995.

11 Nuffield Council on Bioethics. Genetic screening: ethical issues. London: Nuffield Council, 1993.
12 British Medical Association. Human genetics: choice and responsibility. Oxford: Oxford University Press, 1998

13 World Health Organisation. Proposed international guidelines on ethical issues in medical genetics and genetic services. Geneva: WHO, 1998.

14 Wertz DC. What's missing from genetic counseling: a survey of 476 counseling sessions. Fournal of Genetic Counseling 1998;7: 499-500.

15 Sorenson JR, Swazey JP, Scotch NA. Reproductive pasts, reproductive futures: genetic counselling and its effectiveness. New York: Alan R Liss, 1981.

16 Wertz DC. Society and the not-so-new genetics: what are we afraid of? Some future predictions from a social scientist. Four-
nal of Contemporary Health Law and Policy 1997;13:299-346. 